\title{
Preimplantation HLA typing for stem cell transplantation treatment of congenital and acquired bone marrow failures
}

\author{
Anver Kuliev* and Svetlana Rechitsky \\ Reproductive Genetics Institute, 2825 North Halsted Street, Chicago, IL, USA
}

\begin{abstract}
Since we have first introduced preimplantation HLA typing more than 16 years ago, it has become a practical option for stem cell transplantation treatment of congenital and acquired bone marrow failures. This paper summarises our experience of 390 preimplantation HLA typing, representing a part of preimplantation genetic diagnosis (PGD) series, which is the world's largest PGD experience, involving PGD for approximately 500 genetic conditions. The proportion of PGD cases performed combined with HLA typing is steadily increasing, with iimproved awareness of at risk couples regarding PGD as a realistic option for radical treatment of their affected children with bone marrow failures. Preimplantation HLA typing involves detection and transfer of HLA matched unaffecetd embryos, to obtain an HLA compatible offspring as potential donors for their affected siblings. Available results of HLA matched stem cell transplantation treatment following PGD shows a successful hematopoietic reconstitution of patients with different conditions, suggesting that PGD is an efficient approach for HLA matched stem cell transplantation treatment of congetital and acquired bone marrow failures.
\end{abstract}

\section{Introduction}

Increasing number of at risk couples presenting for PGD, also request preimplantation HLA typing to treat their affected children with congenital bone marrow failurrs, requiring an HLA compatible stem cell transplantation treatment. We described the first case of preimplantation HLA typing 16 years ago, performed for Fanconi anemia (FA), which resulted in birth of an unaffected HLA matched child, as donor of cord blood for transplantation treatment $[1,2]$. FA is autosomal recessive disorder, characterized by inherited bone marrow failure, congenital malformations and an increased predisposition to the development of leukemia.. Bone marrow transplantation is the only treatment for this conidition, which restores hematopoiesis in FA patients. However, because any modification of the conditioning may lead to a high rate of transplant-related mortality, the HLA identical cord blood transplantation from a sibling is particularly valuable, to avoid late complications due to severe GVH [3-5].

Parents of this FA child were unaffected carriers of IVS $4+4$ A-T mutation in FANCC gene. Accordingly, their affected 6-yearold daughter had two copies of this mutation, requiring an HLAcompatible donor for bone marrow transplantation. It is of note, that it was an initiative of the parents to attempt PGD, after they have had numerous unsuccessful attempts to get an unaffected HLA comparible offspring following prenatal diagnosis.

PGD was performed at the cleavage stage through biopsy of single blastomeres tested for IVS 4+4 A-T mutation in FANCC gene, using the method of single cell PCR analysis [2]. Nested PCR for specific amplification of HLA A gene exons 2 and 3 was performed by genespecific outer primers, followed by separate second-round PCR with allele specific inner primers. Blastomere genotyping for IVS 4+4 A-T mutation in FANCC gene was performed in 4 clinical cycles, involving the mutation analysis in 33 embryos, including 7 in the first, 4 in second, 8 in third and 14 in fourth cycle. Of 30 embryos with results, 19 were heterozygous carriers, 6 - homozygous affected and 5-homozygous normal. Of 14 embryos tested for mutation in the last cycle, only one was homozygous affected, three were homozygous normal, two did not amplify, with the remaining being heterozygous unaffected.

Testing for HLA A and HLA B in the 24 unaffected embryos, including 19 heterozygous and 5 homozygous normal embryos, revealed 5 heterozygous unaffected embryos for transfer with HLA match for the affected sibling. HLA typing in 14 embryos in the last cycle revealed only one unaffected HLA matched heterozygous embryo, which was transferred back to the patient. This resulted in a clinical pregnancy and birth of a healthy carrier of FANCC gene, whose umbilical cord blood was collected at birth and transplanted to the affected sibling, resulting in a successful hematopoietic reconstitution [2].

This world's first case has opened a new chapter in stem cell transplantation treatment of congenital and acquired diseases using the technology of preimnplantation HLA typing [6-15]. So the present paper describes the progress in PGD for HLA since the description of the above case, involving preimplantatgion HLA typing for a variety of congenital and acquired conditions, demonstrating that PGD has become an acceptable practical option for HLA matched stem cell transplantation treatment for inherited and sporadic bone marrow failures.

\section{Material and methods}

As presented in Table 1, we performed 390 clinical cycles for

Correspondence to: Anver Kuliev, Reproductive Genetics Innovations, 2910 MacArthur Bld, Northbrook IL, 60657, USA, Tel: 847 400-1515; Fax: 847 4001516; E-mail: anverkuliev@hotmail.com

Key words: PGD for inherited disorders, preimplantation HLA typing, stem cell transplantation

Received: November 01, 2016; Accepted: November 14, 2016; Published: November 17, 2016 
preimplantation HLA typing for 181 couples, with a morbid child in the family with congenital or acquired bone marrow failures, Requiring HLA matched stem cell transplantation treatment. PGD cycles were performed using a standard IVF protocol coupled with micromanipulation procedures for the polar body (PB) sampling, or embryo biopsy at the cleavage or blastocyst stage, described in detail elsewhere [16,17]. In brief, the oocytes were tested by sampling of the first and second polar bodies (PB1 and PB2), removed following maturation and fertilization of oocytes, using mechanical micromanipulation technique. The biopsied oocytes were then returned to culture, checked for cleavage and transferred, depending on the genotype of the corresponding PB1 and PB2, which, however, provide the diagnosis only for maternal mutations.

HLA typing or testing for paternal mutations was performed on embryos biopsy samples, obtaned at the cleavage or blastocyst stage, inorder to identify the embryos containing the maternal and paternal chromosomes 6 , identical to the affected siblings, as also described in detail elsewhere $[16,17]$. In brief, HLA haplotypes were tested simultaneously with mutations, using the short tandem repeats (STR) in the HLA region, by applying a multiplex hemi-nested PCR system, involving closely linked STRs in the HLA region (D6S426, D6S291, Ring 3 CA, TAP1, G51152, D6S2447, LH1,DN, D6S273, 9N-2, TNF a,b,c,d; 62, MIC A, MIB, D6S276, D6S439, D6S1624, D6S265, D6S510; D6S248, RF, MOG a,b,c,d, D6S 258, D6S306, D6S464, D6S299, D6S461) [16-18]. The linked markers were chosen to detect the presence of maternal and paternal matching or non-matching chromosomes, avoiding alleles shared by the parents. This allowed obtaining a $100 \%$ HLA match, based on selection of the embryos with the same paternal and maternal chromosome 6 , as in the affected siblings.

\section{Results and discussion}

Preimplantation HLA typing was performed in addition to PGD for
27 different conditions (Table 1) (partially reported previously [2,6,9$11,13]$. As mentioned, a total of 390 clinical cycles were performed, of which 109 were done without PGD, with the sole objective to preselect HLA matched embryos. As seen from these data, hemoglobinopathies weret the most prevalent among among conditions requiring HLA compatible stem cell transplantation, Thiese autosomal recessive conditions affect the production of beta-globin chains with a severe anaemia, requiring regular blood transfusion from six months after birth, So radical treatment of of these patients may be achieved only with stem cell transplantation, but its application is limited to the availability of HLA matched stem cells [19-21], making PGD an attractive option for couples with thalassemic and sickle cell disease. The objective of PGD in these cases is not only to have hemoglobinopathy-free child, but also to ensure that the resulting baby could serve as an HLA compatible donor for bone marrow transplantation for the affected siblings.

A total of 147 of these PGD/HLA cycles were performed for hemoglobinopathies (137 for thalassemia and 10 for sickle cell disease), which resulted in detection and transfer of 131 unaffected HLA matched embryos in 84 cycles, yielding 22 clinical pregnancies and birth of sixteen unaffected HLA matched children. These siblings served as donors of HLA identical stem cells for transplantation treatment, resulting in a successful hematopoietic reconstitution in all of them which have been performed by the present time. The technology is now available for a wider application in those communities where thalassemia and sickle cell disease are highly prevalent. Similar experience was reported from Turkey, where 236 PGD cycles were performed resulting in birth of 70 thalassemia-free children. Bone marrow transplantation led to successful bone marrow reconstitution in all but 4 cases $[14,15]$.

The second frequent indication for preimplantation HLA typing were severe congenital immunodeficiencies (SCID), as without compatible bone marrow transplantation the patients with SCID cannot survive. HLA matched stem cell transplantation improves or

Table 1. Preimplantation HLA Typing.

\begin{tabular}{|c|c|c|c|c|c|c|c|}
\hline Disease & Gene & \# Patient & \# Cycle & \# Transfers & \# Embryo transferred & Pregnancy & Birth \\
\hline HLA + Adrenoleukodystrophy & ABCD1 & 2 & 5 & 1 & 1 & 0 & 0 \\
\hline HLA + Diamond-Blackfan Anemia; DBA & RPS19, RPS24, RPL35A & 6 & 10 & 7 & 10 & 3 & 3 \\
\hline HLA + DMD+Glanzmann's Thrombastenia & ITGA2B, DMD & 1 & 2 & 2 & 4 & 1 & 0 \\
\hline HLA + Dystrophia Myotonica 1 & DMPK & 1 & 2 & 1 & 2 & 1 & 1 \\
\hline HLA+ Ectodermal Dysplasia, Hypohidrotic, With Immune Deficiency & IKBKG & 2 & 9 & 6 & 8 & 2 & 3 \\
\hline HLA + FANCA & FANCA & 16 & 46 & 28 & 40 & 9 & 6 \\
\hline HLA + FANCC & FANCC & 3 & 6 & 6 & 9 & 2 & 2 \\
\hline HLA + FANCD2 & FANCD2 & 1 & 3 & 2 & 3 & 1 & 1 \\
\hline HLA + FANCF & FANCF & 1 & 3 & 2 & 3 & 0 & 0 \\
\hline HLA + FANCI & FANCI & 1 & 2 & 2 & 3 & 0 & 0 \\
\hline HLA + FANCJ & FANCJ & 1 & 3 & 1 & 3 & 0 & 0 \\
\hline HLA + Granulomatous Disease, Chronic, X-Linked; CGD & CYBB & 5 & 11 & 8 & 11 & 4 & 3 \\
\hline HLA + Hemoglobin--Beta Locus; HBB & HBB & 61 & 137 & 78 & 121 & 20 & 15 \\
\hline HLA + Immunodeficiency With Hyper-IgM, TYPE 1; HIGM1 & CD40LG & 6 & 11 & 7 & 11 & 4 & 3 \\
\hline HLA + KRABBE + Aneuploidy & GALC & 1 & 1 & 1 & 2 & 1 & 2 \\
\hline HLA + Sickle Cell Anemia & HBB & 6 & 10 & 6 & 10 & 2 & 1 \\
\hline HLA + Thrombotic Thrombocytopenic Purpura, Congenital; TTP & ADAMTS13 & 1 & 2 & 2 & 4 & 1 & 1 \\
\hline HLA + Wiskott-Aldrich Syndrome; WAS & WAS & 1 & 1 & 0 & 0 & 0 & 0 \\
\hline HLA +PKD1+Aneuploidy & PKD1 & 1 & 1 & 1 & 2 & 1 & 1 \\
\hline HLA Genotyping & & 59 & 118 & 73 & 110 & 25 & 22 \\
\hline HLA+ Piruvate Kinase Deficiency & PKLR & 1 & 2 & 1 & 1 & 0 & 0 \\
\hline HLA Neutropenia Congenital & ELANE & 1 & 1 & 1 & 2 & 0 & 0 \\
\hline HLA Epidermolysis Bullosa & COL7A1 & 1 & 1 & 1 & 1 & 1 & 1 \\
\hline HLA Succinic Semialdehyde Dehydrogenase Deficiency; SSADHD & ALDH5A1 & 1 & 1 & 0 & 0 & 0 & $\mathbf{0}$ \\
\hline HLA +Cardiomyopathy, Familial Hypertrophic, 4 & MYBPC3 & 1 & 2 & 1 & 1 & 1 & 1 \\
\hline Total & 28 & 182 & 391 & 239 & 363 & $80(31.3 \%)$ & 67 \\
\hline
\end{tabular}


completely replenishes the immune system, so PGD is an obvious alternative for inherited forms of SCID, to ensure the birth of unaffected children, who may then serve as a potential stem cell donor progeny for the affected siblings [11]. Our accumulated experience of PGD for SCID includes hyperimmunoglobulin $M$ syndrome (HIGM), X-linked adrenoleukodystrophy (X-ALD), Wiscott-Aldrich syndrome (WAS), and X-linked hypohidrotic ectodermal displasia with immune deficiency (HED-ID) (Table 1). A total of 26 PGD cycles for 14 couples at risk for producing affected progeny with the above conditions were performed, including 11 cycles for HIGM, 5 cycles for adrenoleukodystrophy, 1 for WAS, and 9 for HED-ID, confirming the usefulness of preimplantation HLA matching as part of PGD, which potentially provides an HLA match progeny for treatment of affected siblings.

The other frequent condition, requiring preimplantation HLA typing is FA, for which the first preimplantation HLA typing was performed. as mentioned, to avoid late complications due to severe GVH [3-5]. A total of 23 couples at risk for producing a progeny with FA presented for preimplantation HLA typing, including carriers of IVS 4+4 A-T mutation in FANCC gene, carriers of FANCD2, FANCF, FANCI, FAMCCJ, and FANCA gene mutations [22-27]. Overall, 63 cycles were performed, resulting in transfer of 61 unaffected HLA matched embryos in 41 cycles, yielding twelve unaffected pregnancies and birth of nine FA free and HLA matched children, as potential donors for their siblings.

The data show the usefulness of PGD for SCID, as there is no effective treatment for these conditions other than stem cell transplantation. PGD provides the couples at risk with the option to avoid the affected pregnancy and have an HLA match progeny free of SCID, making possible to have an access to the HLA identical stem cell transplantation through selection and transfer of unaffected embryos which are also HLA match to the sibling. Because the finding of the HLA identical stem cell donor is the key for achieving the success in stem cell transplantation [19-21], a complete cure was observed in the cases of stem cell transplantation in siblings with immunodeficiency.

A special group is represented by preimplantation HLA typing without PGD, which we have first performed for sporadic form of Diamond- Blackfan anemia (DBA) [9]. Our experience of preimplantation HLA matching without testing for causative gene includes 109 IVF cycles initiated for 46 couples wishing to have another child who may also be a potential cord blood donor for the affected siblings with leukemia or other sporadic conditions. A total of 118 clinical cycles from 59 couples were performed, in which 110 HLA matched embryos were pre-selected for transfer in 73 cycles. Proportion of embryos predicted to be HLA matched to the affected siblings was not significantly different from the expected $25 \%$. The transfer of HLA matched embryos resulted in 22 singlet on 25 clinical pregnancies and 22 HLA matched children born. These results suggest that the technique allows preselecting a sufficient number of the HLA matched embryos for transfer to achieve a clinical pregnancies and birth of an HLA matched progeny in the fuirst or second cycle.

Presented data show feasibility of preimplantation HLA matching for families with affected children with bone marrow disorders, who may wish to have another child as a potential HLA matched donor of stem cells transplantation treatment of the affected sibling. As seen from our data, HLA matched embryos were preselected and transferred in all cycles, resulting in clinical pregnancies and birth of HLA matched children in almost every or second transferred cycle. The results also demonstrate the prospect for the application of this approach to other conditions, requiring an HLA compatible donor for stem cell transplantation. This provides an option for those couples who would like to have another child anyway, as they may potentially provide an HLA match progeny for an affected sibling. In addition to leukemias and sporadic forms of DBA, the method may be applied for any other condition, such as for couples having affected children with cancers awaiting an HLA compatible donor with no success for years. As can be seen from the Table 1, there are requests to perform preimplantation HLA typing for the conditions, that are not yet treatable by stem cell transplantation, such muscular dystrophy. We have also performed the test for cebral pulsy cases (not included in this report), although the prospect of treatment of such condition is not clear.

In fact, aneuploidy testing also improves diagnostic accuracy, as the error in the copy number of chromosomes may lead to misdiagnosis in testing for the causative gene and HLA typing. Our data shows at at least $6 \%$ aneuploidy rate for chromosome 6 that could obviously affect the HLA typing results [16]. Taking intoaccount a possibly comparable rates for other chromosomes in which causative genes tested is located, may also affect PGD results. So, patients should be fully aware of limits of the expected successful outcome of the testing, which result in the transfer of HLA matched unaffected embryos in $13.7 \%$, so a bit lower than may have been expected $18 \%$. However, the number of PGD for HLA has been increasing overall, with the increase of also of the proportion of cases, involving a sole preimplantation HLA typing without PGD.

The present experience of PGD for HLA typing described above includes over one thousand cases, resulting in birth of more than two hundred HLA matched children, whose HLA identical stem cells have already been used for a successful transplantation therapy in approximately one hundred affected siblings. The two world's largest experiences, including our and Istanbul Centre series, based on preimplantation HLA typing of over 700 cases shows the high accuracy rate per transfer close to $99 \%$, with the majority performed in combination with PGD for various genetic disorders, involving the pre-selection of unaffected children who were also HLA identical to the affected sibling.

In conclusion, despite ethical issues involved in preimplantation HLA typing [28-31], the presented results show the increasing attractiveness of this option for the couples with affected children requiring HLA compatible stem cell transplantation. So, the couples at risk of having children with congenital bone marrow disorders have to be informed about presently available option not only for avoiding the birth of affected child, but also for selecting a suitable stem cell donor for their affected siblings, which may presently be a realistic hope for treating of siblings with congenital bone marrow failures.

\section{References}

1. Verlinsky Y, Rechitsky S, Schoolcraft W, Strom C, Kuliev A (2000) Designer babiesare they a reality yet. Case report: simultaneous preimplantation genetic diagnosis for Fanconi anaemia and HLA typing for cord blood transplantation. Reprod Biomed Online 1: 31.[Crossref]

2. Verlinsky Y, Rechitsky S, Schoolcraft W, Strom C, Kuliev A (2001) Preimplantation diagnosis for Fanconianemia combined with HLA matching. JAMA285: 3130-3133. [Crossref]

3. Gluckman E, Devergie A, Schaison G, Bussel A, Berger R, et al. (1980) Bone marrow transplantation in Fanconi anaemia. Br J Haematol45: 557-564.[Crossref]

4. Gluckman E, Broxmeyer HA, Auerbach AD, Friedman HS, Douglas GW, et al. (1989) Hematopoietic reconstitution in a patient with Fanconi'sanemia by means of umbilicalcord blood from an HLA-identical sibling. N Engl J Med 321: 1174-1178.[Crossref] 
5. Wagner J, Davies SM, Auerbach AD (1999)Hemotopoietic stem cell transplantation in the treatment of Fanconianemia. In: Forman SJ, Blum KG, Thomas ED [Eds] Hematopoietic Cell Transplantation. 2nd Edn, Malden, Mass: Blackwell Science Inc pp:1204-1219.

6. Rechitsky S, Kuliev A, Tur-Kaspa I, Morris R, Verlinsky Y (2004) Preimplantation genetic diagnosis with HLA matching. Reprod Biomed Online9:210-221.

7. Van de Velde H, Georgiou I, De Rycke M, Schots R, Sermon K, et al. (2004) Novel universal approach for preimplantation genetic diagnosis of beta-thalassaemia in combination with HLA matching of embryos. Hum Reprod 19: 700-708.[Crossref]

8. Kahraman S, Karlilaya G, Sertyel S, Karadayi H, Findicli N, et al.(2004) Clinical Aspects of Preimplantation Genetic Diagnosis of Single Gene Disorders Combined with HLA Typing.Reprod Biomed Online9: 529-532. [Crossref]

9. Verlinsky Y, Rechitsky S, Sharapova T, Morris R, Taranissi M, et al. (2004) Preimplantation HLA testing. JAMA291: 2079-2085.[Crossref]

10. Kuliev A, Rechitsky S, Verlinsky O, Tur-Kaspa I, Kalakoutis G, et al. (2005) Preimplantation diagnosis and HLA typing for hemoglobin disorders. Reprod Biomed Online 1:362-370.

11. Verlinsky Y, Rechitsky S, Sharapova T, Laziuk K, Barsky I, et al. (2007) Preimplantation Diagnosis for Immunodeficiencies. ReprodBioMedicine Online 14: 214-223.

12. Goussetis E, Kokkali G, Petrakou E (2010) Successful Hematopoietic Stem Cell Transplantation in 2 Children with X-Linked Chronic Granulomatous Disease from Their Unaffected HLA-Identical Siblings Selected Using Preimplantation Genetic Diagnosis Combined with HLA Typing. Biol Blood Marrow Transplant16:344-349.

13. Kuliev A, Packalchuk T, Verlinsky O, Rechitsky S (2011) Preimplantation diagnosis efficient tool for human leukocyte antigen matched bone marrow transplantation for thalassemia. Thalassemia Reports 4:2.

14. Kahraman S, Beyazyurek C, Ekmekci CG (2011) Seven years of experience of preimplantation HLA typing: a clinical overview of 327 cycles. Reprod Biomed Online 23: 363-371.[Crossref]

15. Kahraman S (2013) PGD for HLA: Clinical outcome of HLA compatible transplantation following PGD. Reprod Biomed Online 26:S9-S10.

16. Verlinsky Y, Kuliev A (2000) Atlas of Preimplantation Genetic Diagnosis. Parthenon, NY, London.

17. Kuliev A (2012) Practical preimplantation genetic diagnosis. Springer, Heidelberg,New York, London.
18. Foissac A, Salhi M, Cambon-Thomsen A (2000) Microsatellite in the HLA region 1999 update. Tissue Antigens 55: 477-5092.

19. Kuliev A (2012) Practical preimplantation genetic diagnosis. Springer, Heidelberg, New York, London.

20. Lucarelli G, Andreani M, Angelucci E (2002) The cure of thalassemia by bone marrow transplantation. Blood Rev 16: 81-85.[Crossref]

21. Gaziev J, Lucarelli G (2005) Stem cell transplantation for thalassaemia. Reprod Biomed Online 10: 111-115.[Crossref]

22. Gaziev J, Lucarelli G (2010) Allogeneic cellular gene therapy for hemoglobinopathies. HematolOncolClin North Am 24: 1145-1163.[Crossref]

23. Strathdee CA, Duncan AM, Buchwald M (1992) Evidence for at least four Fancon anaemia genes including FACC on chromosome 9. Nat Genet 1: 196-198.[Crossref]

24. Strathdee CA, Gavish H, Shannon WR, Buchwald M (1992) Cloning of cDNAs for Fanconi's anaemia by functional complementation. Nature356: 763-767.

25. Whitney MA, Saito H, Jakobs PM, Gibson RA, Moses RE, et al. (1993) A common mutation in the FACC gene causes Fanconi anaemia in Ashkenazi Jews. Nat Genet 4: 202-205.[Crossref]

26. Gibson RA, Morgan NV, Goldstein LH, Pearson IC, Kesterton IP, et al. (1996) Novel mutations and polymorphisms in the Fanconianemia group C gene. Hum Mutat8: 140148.[Crossref]

27. Mitsunaga S1, Tokunaga K, Kashiwase K, Akaza T, Tadokoro K, et al. (1998) A nested PCR-RFLP method for high-resolution typing of HLA-A alleles. Eur J Immunogenet 25: 15-27.[Crossref]

28. Blasczyk R, Huhn U, Wehling J, Huhn D, Salama A (1995) Complete subtyping of the HLA-A locus by sequence-specific amplification followed by direct sequencing or single-strand confirmation polymorphism analysis. Tissue Antigens 46:86-95.

29. Edwards RG (2004) Ethics of PGD: thoughts on the consequences of typing HLA in embryos. Reprod Biomed Online9: 222-224.[Crossref]

30. Fost NC (2004) Conception for donation. JAMA291: 2125-2126.[Crossref]

31. Devolder K (2005) Preimplantation HLA typing: having children to save our loved ones. J Med Ethics 31: 582-586.[Crossref]

Copyright: $(02016$ Kuliev A. This is an open-access article distributed under the terms of the Creative Commons Attribution License, which permits unrestricted use, distribution, and reproduction in any medium, provided the original author and source are credited. 